\title{
Efeitos da densidade de plantas no rendimento comercial de espigas verdes de cultivares de milho
}

\author{
Disraeli R da Rocha ${ }^{1}$; Domingos Fornasier Filho ${ }^{2}$; José Carlos Barbosa ${ }^{3}$ \\ ${ }^{1}$ UFPI-Depto. Fitotecnia; ${ }^{2}$ UNESP-FCAV-Prod. Vegetal, Rodov. Prof. Paulo Donato Castellane, km 5, 14870-000 Jaboticabal-SP; \\ ${ }^{3}$ UNESP-FCAV-Ciências Exatas; dfitotec@ufpi.br
}

\begin{abstract}
RESUMO
A cultura do milho-verde é alternativa de grande valor econômico para pequenos e médios agricultores, principalmente em áreas irrigadas. O objetivo do trabalho foi avaliar o rendimento comercial de espigas verdes e de outras características das plantas de seis cultivares de milho, submetidas a quatro densidades populacionais. Utilizou-se o delineamento experimental em parcelas subdivididas, com seis tratamentos principais (cultivares), quatro tratamentos secundários (densidade populacional) e quatro repetições dispostas em blocos casualizados. As cultivares Cativerde 2, P3232, BM3061 e AG4051 apresentaram as maiores alturas de plantas, enquanto SWB551 foi a mais reduzida. A menor altura média de inserção da primeira espiga foi obtida pela cultivar SWB551. As cultivares AG4051, AG1051, BM3061 e P3232 foram superiores às demais em comprimento e no número de espigas comerciais despalhadas. Entre as quatro densidades populacionais, 50.000 plantas $\mathrm{ha}^{-1}$ foi a que promoveu o mais alto rendimento de espigas. O híbrido P3232 apresentou ciclo e acúmulo térmico superiores às demais cultivares, com BM3061 sendo a mais precoce.
\end{abstract}

Palavras-chave: Zea mays, híbridos, variedade, milho doce, acúmulo térmico.

\begin{abstract}
Effects of plant density on yield of green ears of corn cultivars

Green corn is a crop of great economic value for small and medium farmers, especially in irrigated areas. The objective of the study was to assess the yielding of green ears and other features of six cultivars of corn, undergoing sowing density with irrigation. The experimental design in split plots, with six main treatments (cultivars), four secondary treatments (densities) and four replications arranged in randomized blocks was utilized. The Cativerde 2, P3232, BM3061 and AG4051 cultivars showed the greatest heights of plants, whereas SWB551 was the smallest one. The smallest average height of insertion of the first ear was obtained by SWB551. AG4051, AG1051, BM3061 and P3232 outsized and outnumbered the other ones in terms of commercial ears scattered. Among the four planting densities tested, 50,000 plants/ha provided the highest corn ear yielding. The P3232 hybrid features higher thermal cycle and accumulation in relation to other cultivars, with BM3061 being the most precocious.
\end{abstract}

Keywords: Zea mays, hybrids, variety, sweet-corn, growing degreedays.

(Recebido para publicação em 18 de junho de 2010; aceito em 6 de junho de 2011)

(Received on June 18, 2010; accepted on June 6, 2011)

$\mathrm{O}$ milho é uma das culturas mais importantes para a humanidade, devido a seu alto potencial produtivo e às diversas formas de utilização na alimentação humana e animal, in natura e na indústria de alta tecnologia. $\mathrm{O}$ mercado de milho para alimentação humana, embora seja, ainda, relativamente pequeno, é promissor, em especial na região Nordeste do País, onde o cultivo de milho-verde ocorre, atualmente, durante todo o ano, inclusive sob condições de irrigação.

Um aspecto relevante no manejo cultural para a produção de milho-verde é que essa exploração geralmente é conduzida em pequena escala, em médias lavouras, e a colheita é manual (Cruz \& Pereira Filho, 2003). Na região da Grande Teresina o cultivo de milho-verde irrigado é realizado por pequenos produtores rurais, na maioria, proprietários de terras, em área média em torno de 2 hectares, com produtividade média ao redor de 20-25 mil espigas verdes/ha ou de 8 a 10 t de espigas/ha.

A manipulação do arranjo de plantas de milho, por meio de alterações na densidade de plantas, de espaçamentos entre linhas, de distribuição de plantas na linha e na variabilidade entre plantas, é uma das práticas de manejo mais importantes para maximizar a interceptação da radiação solar, otimizar o seu uso e potencializar o rendimento de grãos (Argenta et al., 2001).

Barbieri et al. (2005), avaliando o comportamento de dois híbridos de milho doce submetidos a quatro espaçamentos entre fileiras e cinco densidades de plantio, em Uberlândia-MG, observaram que a produtividade das espigas aumentou com o incremento da população de plantas e um decréscimo linear de 0,6 e $0,09 \mathrm{~mm}$ no comprimento e no diâmetro da espiga, respectivamente, decorrente de aumento proporcional de 1000 plantas na população.

Vieira (2007), avaliando o efeito de densidades de plantio no comportamento agronômico de cultivares de milho para produção de espigas verdes na região de Ponta Grossa-PR, constatou que o número e a produtividade de espigas comerciais são influenciados negativamente pelo aumento da pressão populacional. Cruz \& Pereira Filho (2003), sintetizando resultados de trabalhos de vários autores, concluíram que o estande para a produção de milho-verde deve variar entre 35 e 55 mil plantas/ha, menor que a densidade normalmente utilizada para a produção de grãos. 
O milho consumido no estádio de grão leitoso ou pastoso, tem sido produzido com o uso de cultivares comuns de endosperma normal, promovendo, dessa forma, grandes variações nas texturas dos grãos comercializados e evidenciando o pouco conhecimento que os produtores têm sobre a existência de cultivares desenvolvidas especificamente para esse fim, com características mais atrativas para o consumidor (Paiva Junior et al., 2001). Há centenas de cultivares de milho disponíveis no mercado de sementes no Brasil, das quais quinze são recomendadas pelas firmas produtoras de semente como apropriadas para milho-verde (Pereira Filho et al., 2003).

A recomendação de cultivares específicas para produção de milho-verde, aliadas à adequada densidade populacional e à adubação equilibrada são ações responsáveis para o bom desempenho da cultura (Farinelli et al., 2003). Avaliar novas cultivares de milho, em espaçamento reduzido entre as linhas e com diferentes densidades de plantas se faz necessário, uma vez que as novas cultivares disponíveis no mercado são mais produtivas, têm porte mais baixo e arquitetura foliar mais ereta, em relação aos materiais mais antigos, o que favorece a adoção de arranjo de plantas que permita distribuir de maneira mais eqüidistante as plantas na área, proporcionando aumentos da produtividade (Alvarez et al., 2006).

O objetivo do trabalho foi avaliar o rendimento comercial de espigas verdes e outras características de seis cultivares de milho, submetidas a diferentes densidades de plantas, com a utilização de irrigação por aspersão.

\section{MATERIAL E MÉTODOS}

$\mathrm{O}$ experimento foi conduzido em área experimental do Colégio Agrícola de Teresina, da Universidade Federal do Piauí, localizada em Teresina-PI ( $5^{\circ} 5^{\prime} \mathrm{S}, 42^{\circ} 48^{\prime} \mathrm{W}$, altitude $78 \mathrm{~m}$ ). A região apresenta clima tropical com chuvas de verão e outono, com precipitação média anual de $1.377 \mathrm{~mm}$, sendo mais elevada nos meses de março e abril. Apresenta evapotranspiração potencial média anual de $2.973 \mathrm{~mm}$, umidade relativa do ar média anual de $69,9 \%$, insolação total anual de 2.625 horas, temperatura média anual de $28^{\circ} \mathrm{C}$, amplitude térmica de $11,5^{\circ} \mathrm{C}$, fotoperíodo médio anual de 12 h (19/dia), com mínimo de 11 h (46/ dia) e máximo de 12 h (29/dia) (Medeiros, 2006).

As cultivares de milho avaliadas foram um híbrido simples (SWB551, de caráter superdoce), três híbridos triplos (P3232, AG4051 e BM3061), um híbrido duplo (AG1051) e uma cultivar (Cativerde 2), submetidas a quatro densidades de plantas $(30 ; 40 ; 50$ e 60 mil plantas ha-1).

Utilizou-se o delineamento experimental em parcelas subdivididas com seis tratamentos principais (cultivares), quatro tratamentos secundários (densidades de plantas) e quatro repetições dispostas em blocos casualizados. Cada sub-parcela foi constituída por seis fileiras, com cinco metros de comprimento, espaçadas $0,6 \mathrm{~m}$, considerando-se como área útil as quatro centrais.

O solo da área experimental é do tipo Argissolo Vermelho-Amarelo, eutrófico, textura arenosa e relevo suave ondulado (Cordeiro, 2003 ), ocupado anteriormente com culturas de milho e feijão. O sistema de preparo de solo empregado foi o convencional, por meio de aração e de duas gradagens niveladoras. De acordo com os resultados da análise química do solo (na profundidade de 0 a $0,20 \mathrm{~m}$ ) foram obtidos os seguinte valores: $\mathrm{pH}$ $(\mathrm{KCl} \mathrm{N})=5,8 ; \mathrm{MO}=6 \mathrm{~g} \mathrm{dm}^{-3} ; \mathrm{P}$ resina $=$ $4 \mathrm{mg} \mathrm{dm}^{-3} ; \mathrm{K}=1,0 \mathrm{mmol}_{\mathrm{c}} \mathrm{dm}^{-3} ; \mathrm{Ca}=$ $15 \mathrm{mmol}_{\mathrm{c}} \mathrm{dm}^{-3} ; \mathrm{Mg}=6,0 \mathrm{mmol}_{\mathrm{c}} \mathrm{dm}^{-3}$; $\mathrm{H}+\mathrm{Al}=17 \mathrm{mmol}_{\mathrm{c}} \mathrm{dm}^{-3} ; \mathrm{SB}=22 \mathrm{mmol}_{\mathrm{c}}$ $\mathrm{dm}^{-3} ; \mathrm{T}=39 \mathrm{mmol}_{\mathrm{c}} \mathrm{dm}^{-3} ; \mathrm{e} \mathrm{V}=56 \%$. Na calagem, realizada sessenta dias antes da semeadura, foi utilizado calcário com $34 \%$ de $\mathrm{CaO}, 14 \%$ de $\mathrm{MgO}, 90 \%$ de PRNT, em quantidade suficiente para elevar a saturação por bases a $70 \%$. A adubação de semeadura, efetuada por meio do formulado 5-30-15, na dose de $400 \mathrm{~kg} \mathrm{ha}^{-1}$, foi feita manualmente, no fundo de sulcos com $15 \mathrm{~cm}$ de profundidade, juntamente com esterco de curral, este, em quantidade equivalente a $15 \mathrm{t} \mathrm{ha}^{-1}$. A adubação de cobertura foi realizada manualmente, a $20 \mathrm{~cm}$ das fileiras das plantas e incorporada ao solo em sulcos com $5 \mathrm{~cm}$ de profundidade. No caso do adubo nitrogenado (uréia), foi parcelado em duas doses iguais, de $60 \mathrm{~kg} \mathrm{ha}^{-1} \mathrm{de} \mathrm{N}$, aplicando-se a primeira dose quando a planta contava com 4 a 5 folhas e a segunda, no estádio de 8 a 10 folhas completamente desenvolvidas. A adubação potássica de cobertura foi realizada de uma única vez, na dose de $60 \mathrm{~kg} \mathrm{ha}^{-1}$ de $\mathrm{K}_{2} \mathrm{O}$, utilizando como fonte o cloreto de potássio, juntamente com a uréia, na primeira adubação de cobertura.

A irrigação por aspersão, via sistema convencional, com turno de rega diário, foi realizada utilizando uma lâmina d'água crescente com a evolução do crescimento e desenvolvimento da planta, atingindo-se lâminas d'água da ordem de $8 \mathrm{~mm}$ diários nos estádios V18 (planta com dezoito folhas) a R3 (grão leitoso).

A semeadura do milho foi realizada em 12 de março de 2007, manualmente, colocando-se por cova duas sementes, a distâncias correspondentes às densidades populacionais desejadas após o desbaste $(55,5 ; 41,6 ; 33,3$ e $27,75 \mathrm{~cm}$ entre as covas para densidades de 30 , 40, 50 e 60 mil plantas ha $^{-1}$, respectivamente). $O$ desbaste foi realizado quando as plantas apresentavam três a quatro folhas totalmente expandidas, deixando-se uma planta por cova.

As colheitas foram realizadas manualmente, entre 65 e 72 dias após a emergência, à medida que as espigas foram atingindo o ponto de milho-verde, ou seja, quando os grãos se apresentavam com cerca de 70 a $80 \%$ de umidade, entre os estádios leitoso e pastoso.

Foram avaliadas em todas as plantas contidas na área útil de cada parcela as seguintes características: altura de plantas (determinada pela distância do nível do solo até a inserção da folha-bandeira); altura da inserção da primeira espiga (determinada pela distância do nível do solo até a inserção da primeira espiga); comprimento $(\mathrm{cm})$ das espigas comerciais despalhadas; número de espigas comerciais despalhadas. Avaliou-se, ainda, a duração do período da emergência (VE) ao pendoamento (VT) em dias (DAE), e o acúmulo em graus-dia (GD), em que $50 \%$ das plantas da área útil apresentavam o pendão liberando pólen; duração do período da emergência à colheita de espigas verdes com 
grãos leitoso-pastosos (R3), em DAE e GD. Foram consideradas espigas comerciais despalhadas aquelas com tamanho superior a $15 \mathrm{~cm}$, conforme Paiva Junior et al. (2001) e com diâmetro superior a 4 $\mathrm{cm}$, granadas e isentas de insetos-praga e doenças.

Para o cálculo de GD, consideraram-se $8^{\circ} \mathrm{C}$ como temperatura-base e temperatura mínima, por ser considerada como a mais adequada (Brunini, 1995; Barbano et al., 2000) e $35^{\circ} \mathrm{C}$ (Guiscem et al., 2000) como temperatura máxima.

Os dados obtidos foram submetidos à análise de variância pelo teste $\mathrm{F}$ de acordo com o delineamento experimental adotado. As médias foram comparadas pelo teste de Tukey a 5\% de probabilidade. Para avaliar o efeito da densidade populacional sobre as características avaliadas, utilizou-se a análise de regressão polinomial até $3^{0}$ grau, de acordo com o software ESTAT (1993).

\section{RESULTADOS E DISCUSSÃO}

A altura de plantas foi influenciada pelas cultivares, pelas densidades e pela interação entre os dois fatores (Tabela 1). As cultivares Cativerde 2, P3232, BM3061 e AG1051 apresentaram as maiores alturas de plantas. As cultivares AG1051, BM3061, P3232, Cativerde 2 e SWB551 expressaram incrementos positivos e lineares nesse componente, com o acréscimo da densidade populacional, ao passo que a cultivar AG4051 apresentou incrementos significativos de acordo com uma equação quadrática, até a população de 60 mil plantas ha ${ }^{-1}$ (Figura 1). Os valores crescentes para altura de plantas, com o aumento da densidade populacional, também foram observados por Paiva Junior et al. (1998), Barbieri et al. (2005) e Alvarez et al. (2006), contrastando com os resultados obtidos por Silva et al. (2007). Provavelmente, sob altas densidades populacionais, ocorra interferência na qualidade da luz que atinge o interior do dossel, incrementando a quantidade de vermelho distante (VD) e diminuindo a quantidade do vermelho (V). O aumento da relação VD/V pode alterar a arquitetura de planta, estimulando a dominância apical, com a elongação dos entrenós (Ballaré et al., 2000; Sangoi,

Tabela 1. Médias de altura de planta, altura da inserção da primeira espiga, comprimento e número de espigas verdes comerciais despalhadas, de seis cultivares de milho submetidas a quatro densidades de plantas (averages of plant height, height of insertion of the first ear, length and number of commercial green ears without straw of six corn cultivars undergoing four planting densities). Teresina, UFPI, 2007.

\begin{tabular}{|c|c|c|c|c|}
\hline \multirow[b]{2}{*}{ Fontes de Variação } & \multirow{2}{*}{$\begin{array}{c}\text { Altura } \\
\text { de planta } \\
\text { (cm) }\end{array}$} & \multirow{2}{*}{$\begin{array}{c}\text { Altura da } \\
1^{\mathrm{a}} \text { espiga } \\
(\mathrm{cm})\end{array}$} & \multicolumn{2}{|c|}{ Espiga despalhada } \\
\hline & & & $\begin{array}{c}\text { Comprimento } \\
\text { (cm) }\end{array}$ & $\begin{array}{l}\text { Número } \\
\text { (mil/ha) }\end{array}$ \\
\hline \multicolumn{5}{|c|}{ Densidade (plantas/ha) (D) } \\
\hline 30.000 & $202 \mathrm{~d}$ & $103 \mathrm{~d}$ & $17,9 \mathrm{a}$ & $20,5 \mathrm{c}$ \\
\hline 40.000 & $208 \mathrm{c}$ & $108 \mathrm{c}$ & $17,1 \mathrm{~b}$ & $26,6 \mathrm{~b}$ \\
\hline 50.000 & $217 b$ & $113 \mathrm{~b}$ & $16,7 \mathrm{c}$ & 29,9 a \\
\hline 60.000 & $225 \mathrm{a}$ & $119 \mathrm{a}$ & $16,2 \mathrm{~d}$ & $26,1 \mathrm{~b}$ \\
\hline Teste F & $152,10 * *$ & $106,44 * *$ & $66,24 * *$ & $31,41 * *$ \\
\hline DMS (Tukey) a 5\% & 3,09 & 2,50 & 0,33 & 3,93 \\
\hline \multicolumn{5}{|l|}{ Cultivar (C) } \\
\hline BM3061 & $217 \mathrm{a}$ & $118 \mathrm{a}$ & $17,2 \mathrm{ab}$ & $30,8 \mathrm{a}$ \\
\hline AG1051 & $209 \mathrm{~b}$ & $111 \mathrm{ab}$ & $17,7 \mathrm{a}$ & $29,2 \mathrm{a}$ \\
\hline P3232 & $218 \mathrm{a}$ & $117 \mathrm{ab}$ & $17,6 \mathrm{a}$ & $28,4 \mathrm{a}$ \\
\hline AG4051 & $215 \mathrm{ab}$ & $110 \mathrm{~b}$ & $17,2 \mathrm{ab}$ & $27,5 \mathrm{a}$ \\
\hline Cativerde 2 & $222 \mathrm{a}$ & $109 \mathrm{~b}$ & $16,5 \mathrm{bc}$ & $20,3 \mathrm{~b}$ \\
\hline SWB 551 & $196 \mathrm{c}$ & $101 \mathrm{c}$ & $15,8 \mathrm{c}$ & $18,3 \mathrm{~b}$ \\
\hline Teste F & $39,03 * *$ & $12,55 * *$ & $13,81 * *$ & $22,68 * *$ \\
\hline DMS (Tukey) 5\% & 6,83 & 8,21 & 0,88 & 2,25 \\
\hline Teste F (D x C) & $2,21 *$ & $2,33 *$ & $0,82^{\mathrm{ns}}$ & $0,86^{\mathrm{ns}}$ \\
\hline CV (\%) Cultivar & 2,78 & 6,41 & 4,50 & 13,25 \\
\hline CV (\%) Densidade & 1,89 & 2,94 & 2,55 & 11,41 \\
\hline
\end{tabular}

Médias seguidas da mesma letra não diferem entre si, pelo teste de Tukey, a 5\% de probabilidade. $* *$ e $*=$ significativo a $1 \%$ e $5 \%$ de probabilidade pelo teste $\mathrm{F}$, respectivamente; $\mathrm{NS}=$ não-significativo; $\mathrm{D} \times \mathrm{C}=$ interação densidades por cultivares (averages followed by the same letter do not differ, by Tukey test, $5 \%$ probability.** and $*=$ significant at $1 \%$ and $5 \%$ probability by $\mathrm{F}$ test, respectively, $\mathrm{NS}=$ non-significant, $\mathrm{D} \times \mathrm{C}=$ densities per cultivars interaction).

2000).

Para altura de inserção da primeira espiga constatou-se que houve influência das cultivares (C), densidade populacional (D) e da interação C x D (Tabela 1). As maiores alturas foram obtidas pelas cultivares BM3061, P3232 e AG1051. Nas cultivares AG4051, BM3061, P3232, Cativerde 2 e SWB551 observou-se um acréscimo linear em altura com o aumento da densidade populacional. A cultivar AG1051 teve incrementos significativos na altura de inserção da primeira espiga, de acordo com uma equação quadrática, até a população de 60 mil plantas ha-1 (Figura 1).

O comprimento de espigas comerciais despalhadas foi influenciado pelas cultivares e pela densidade populacio- nal (Tabela 1). As cultivares AG4051, AG1051, P3232 e BM3061 contiveram espigas comerciais com comprimentos superiores aos dos outros materiais avaliados. A SWB551, apesar de apresentar espigas com comprimento inferior aos demais híbridos, é interessante por se tratar de cultivar de milho superdoce que, de acordo com Lemos et al. (2002), tem potencial para textura superior, com alto teor de açúcares e pouco amido no endosperma. Esse componente foi influenciado pelo incremento na densidade populacional, como pode ser observado na análise de regressão (Figura 1). Entretanto, mesmo sob populações de 60.000 plantas, as espigas revelaram comprimento comercial aceitável. Paiva Junior et al. (1998), Cruz \& Pereira 
Tabela 2. Médias do período de duração, em dias após a emergência (DAE) e em unidade calórica (GD), para florescimento masculino (VT) e colheita de espigas verdes comerciais despalhadas $\left(\mathrm{R}_{3}\right)$, de seis cultivares de milho submetidas a quatro densidades de plantas (average period of time, in days after emergence (DAE) and caloric unit (GD) for male flowering (VT) and harvest of marketable green ears without straw $\left(\mathrm{R}_{3}\right)$, of six cultivars of corn subjected to four plant densities). Teresina, UFPI, 2007.

\begin{tabular}{lccccc}
\hline \multirow{2}{*}{ Fontes de variação } & \multicolumn{2}{c}{ VT } & & \multicolumn{2}{c}{$\mathbf{R}_{3}$} \\
\cline { 2 - 3 } \cline { 5 - 6 } Densidade (plantas ha-1) (D) & GA & GD & & GD \\
\hline 30.000 & $43,1 \mathrm{~d}$ & $1002 \mathrm{c}$ & & $64,2 \mathrm{c}$ & $1494 \mathrm{c}$ \\
40.000 & $43,6 \mathrm{c}$ & $1014 \mathrm{~b}$ & & $64,8 \mathrm{~b}$ & $1508 \mathrm{~b}$ \\
50.000 & $44,2 \mathrm{~b}$ & $1028 \mathrm{a}$ & & $65,3 \mathrm{a}$ & $1517 \mathrm{a}$ \\
60.000 & $44,5 \mathrm{a}$ & $1034 \mathrm{a}$ & & $65,5 \mathrm{a}$ & $1523 \mathrm{a}$ \\
\hline Teste F & $81,95 * *$ & $85,33 * *$ & & $36,33 * * *$ & $25,35 * *$ \\
DMS (Tukey) a 5\% & 0,25 & 5,84 & & 0,35 & 9,23 \\
\hline Cultivar (C) & & & & \\
\hline P3232 & $46,3 \mathrm{a}$ & $1075 \mathrm{a}$ & & $68,3 \mathrm{a}$ & $1586 \mathrm{a}$ \\
SWB551 & $43,9 \mathrm{~b}$ & $1021 \mathrm{~b}$ & & $65,6 \mathrm{~b}$ & $1524 \mathrm{~b}$ \\
CAtiverde 2 & $43,9 \mathrm{~b}$ & $1017 \mathrm{~b}$ & & $65,2 \mathrm{bc}$ & $1519 \mathrm{~b}$ \\
AG4051 & $43,7 \mathrm{~b}$ & $1015 \mathrm{~b}$ & & $64,8 \mathrm{c}$ & $1507 \mathrm{~b}$ \\
AG1051 & $43,4 \mathrm{~b}$ & $1010 \mathrm{~b}$ & & $63,8 \mathrm{~d}$ & $1484 \mathrm{c}$ \\
BM3061 & $42,1 \mathrm{c}$ & $980 \mathrm{c}$ & & $62,1 \mathrm{e}$ & $1441 \mathrm{~d}$ \\
\hline Teste F & $31,17 * *$ & $28,42 * *$ & & $139,92 * *$ & $88,07 * *$ \\
DMS & 1,10 & 26,57 & & 0,80 & 23,47 \\
Teste F (D x C) & $1,38 \mathrm{~ns}$ & $1,55 \mathrm{~ns}$ & & $1,50 \mathrm{~ns}$ & $1,17 \mathrm{~ns}$ \\
CV (\%) Cultivar & 2,19 & 2,27 & & 1,08 & 1,35 \\
CV (\%) Densidade & 0,76 & 0,75 & & 0,71 & 0,80 \\
\hline
\end{tabular}

Médias seguidas da mesma letra não diferem entre si, pelo teste de Tukey, a 5\% de probabilidade. $* *$ e $*=$ significativo a $1 \%$ e $5 \%$ de probabilidade, pelo teste $\mathrm{F}$, respectivamente; $\mathrm{NS}=$ não-significativo; D x C = interação densidades e cultivar (averages followed by same letter do not differ by Tukey test, at $5 \%$ probability. $* *$ and $*=$ significant at $1 \%$ to $5 \%$ of probability by $\mathrm{F}$ test, respectively, $\mathrm{NS}=$ not significant, $\mathrm{D} \times \mathrm{C}=$ densities per cultivars interaction).

Filho (2002) e Silva et al. (2007), similarmente ao observado neste trabalho, verificaram que o aumento da densidade de plantas promoveu a redução do comprimento de espigas.

A redução no comprimento de espigas com a elevação da população de plantas pode ser atribuída ao aumento da competição por nutrientes e luz, e a conseqüente redução de fotoassimilados. Sob baixas densidades populacionais, a produção individual por planta é máxima (Fornasieri Filho, 2007). Em menores densidades, cada planta recebe maior quantidade de luz e tende a produzir espigas maiores em função da eficiência na interceptação da radiação incidente (Argenta et al., 2001), quando outros fatores ambientais são favoráveis.

Com relação ao número de espigas
$57.500,42.500,55.000,43.333$ e 55.000 plantas ha ${ }^{-1}$, respectivamente (Figura 1). Em maiores densidades, há tendência de menor produção de espigas com padrão comercial, pois cada planta recebe menores quantidades de nutrientes, água e luz, o que pode ter reduzido o metabolismo celular, com conseqüente diminuição no comprimento e diâmetro de espigas. Cruz \& Pereira Filho (2003) e Fornasieri Filho (2007) relataram que o rendimento de uma lavoura de milho eleva-se com o aumento da densidade de plantas até atingir uma densidade ótima, a partir da qual ocorre decréscimo progressivo de produtividade.

Quanto à duração do período compreendido entre a emergência e o florescimento masculino, com base em dias após emergência (DAE) e no acúmulo térmico (GD), ocorreram diferenças significativas entre cultivares e entre densidades de plantas (Tabela 2). Para este período a cultivar P3232 foi a mais tardia (46,3 DAE e 1075 GD), com BM3061 constituindo-se na mais precoce (42,1 DAE e 980 GD). Para esse mesmo período, Brunini et al. (1995), obtiveram resultados que variaram de 49 a 59 DAE e Oliveira (1997) registrou resultados com 48 e 56 para DAE e entre 672 e 798 para GD. No presente experimento, os valores de DAE obtidos foram inferiores aos destes autores, provavelmente por influência da temperatura de Teresina que, durante o experimento, teve amplitude de 21,1 a $33,7^{\circ} \mathrm{C}$.

Quanto à duração do período compreendido entre a emergência e a colheita de espigas verdes, observou-se diferenças entre as cultivares, tanto para DAE quanto para GD (Tabela 2). Com relação às cultivares, destacou-se o híbrido P3232, alcançando os maiores valores de DAE $(68,3)$ e GD (1586); os menores valores em DAE $(62,1)$ e GD (1441) foram expressos por BM3061. A duração do período de emergência à colheita de espigas verdes, em DAE e em GD, independentemente das cultivares, cresceu da menor para a maior população de plantas (Figura 2). Também, Vieira (2007) verificou no híbrido super-doce SWB551 que ocorreu um atraso de quatro dias entre a menor e a maior densidade de plantas. 


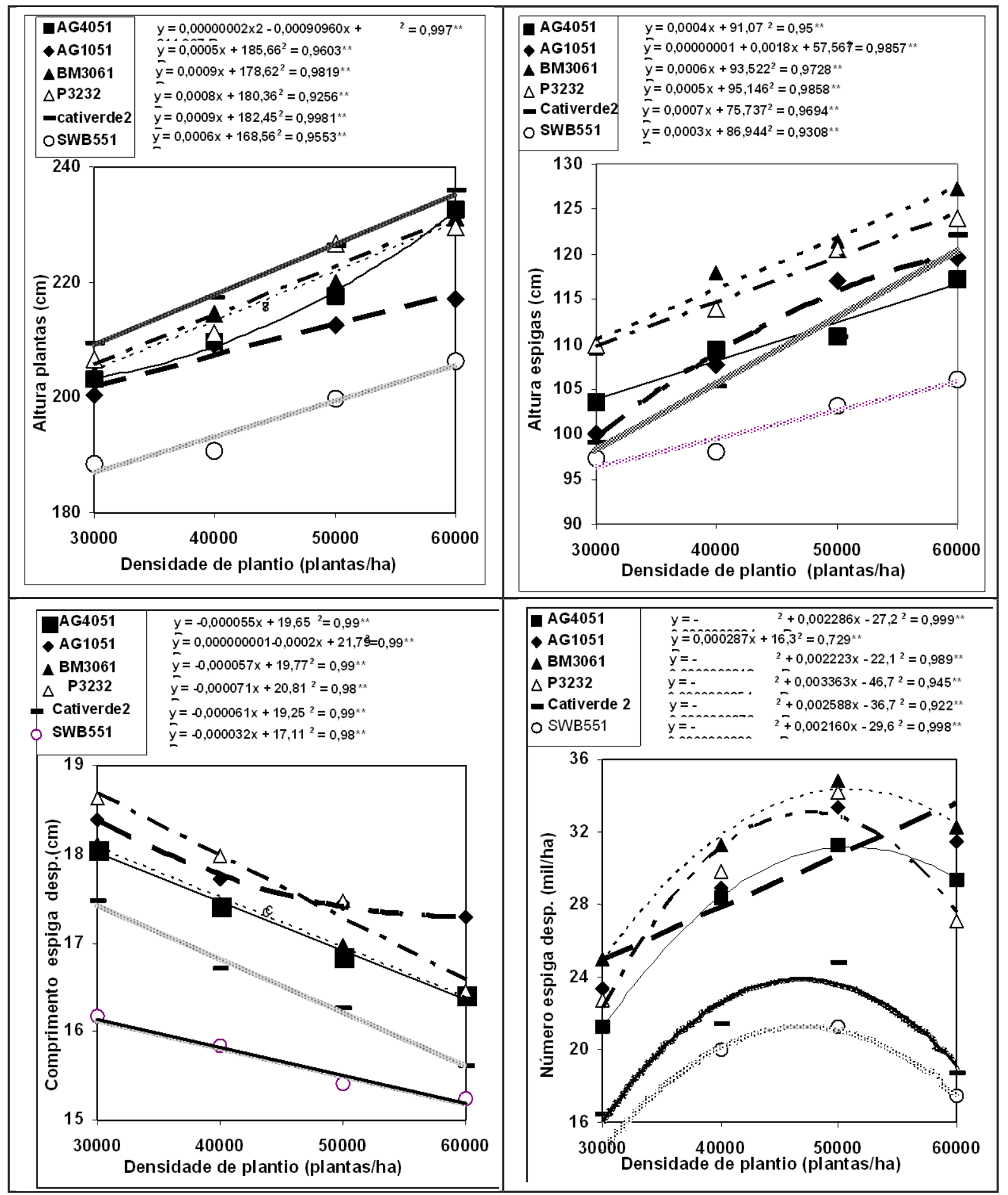

Figura 1. Altura de plantas, altura de inserção da primeira espiga, comprimento de espigas verdes comerciais despalhadas e número de espigas comerciais despalhadas, de seis cultivares de milho em função de quatro densidades de plantas (plant height, height of insertion of the first ear, length of marketable green ears without straw and number of marketable ears of six cultivars of corn, obtained with four planting densities). Teresina, UFPI, 2007.

Conclui-se que o incremento na densidade populacional em milho aumenta a altura da planta e da primeira espiga e reduz o comprimento das espigas. Todas as cultivares contiveram espigas verdes com comprimento e número de espigas adequados à comercialização, com destaques para o híbrido duplo AG1051 e os híbridos triplos AG4051, BM3061 e P3232. AG1051 revelou a maior capacidade de suportar altas densidades de plantas, uma vez que ob- teve maior comprimento da espiga e do número de espigas nas populações mais altas. P3232 apresenta, ciclo e acúmulo térmico superiores às demais cultivares, com BM3061 constituindo-se no mais precoce. 


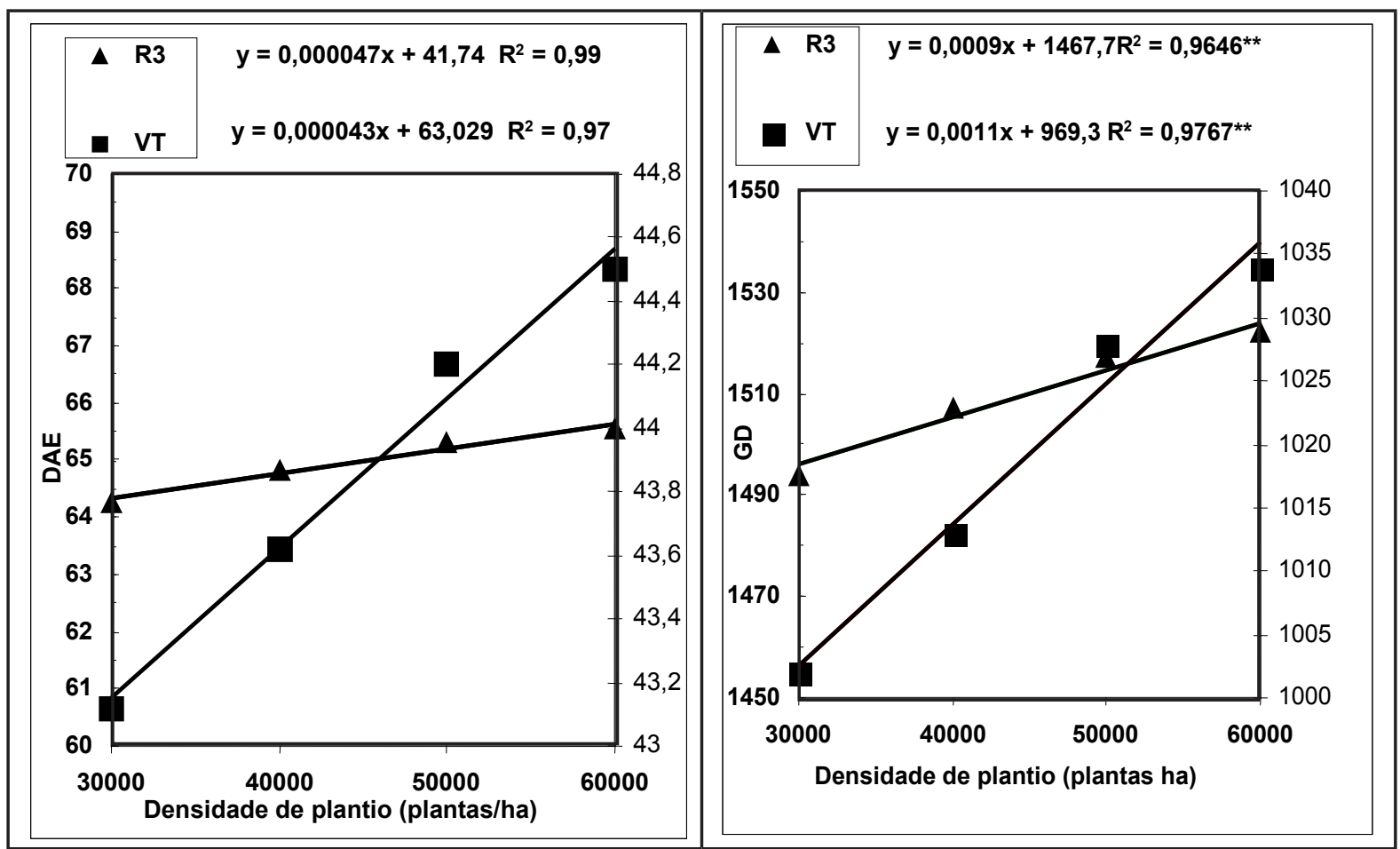

Figura 2. Duração do período da emergência ao florescimento masculino (VT) e da emergência à colheita de espigas verdes ( $\left.\mathrm{R}_{3}\right)$, em $\mathrm{DAE}$ e GD, em função das densidades de plantas, nas seis cultivares (duration of the period from the emergence to male flowering (VT) and from emergence to harvest of green ears $\left(\mathrm{R}_{3}\right)$ in DAE and GD, as a result of plant densities, in the six cultivars). Teresina, UFPI, 2007.

\section{REFERÊNCIAS}

ALVAREZ CGD; PINHO RG; BORGES ID. 2006. Avaliação de características agronômicas e de produção de forragem e de grãos de milho em diferentes densidades de semeadura e espaçamento entre linhas. Ciência Agrotécnica 30: 402-408.

ARGENTA G; SILVA PRF; SANGOI L. 2001. Arranjo de plantas em milho: análise do estado da arte. Ciência Rural 31: 1075-1084.

BALLARÉ CL; SCOPEL AL; SANCHEZ RA. 2000. Plant photomorphogenesis in canopies, crop growth, and yield. Horticultural Science 30: 1172-1181.

BARBANO MT; DUARTE AP; BRUNINI O; RECO PC; PATERNIANI MEAGZ; KANTHACK RAD. 2000. Acúmulo térmico e duração do subperíodo semeaduraflorescimento masculino e cultivares de milho no Estado de São Paulo. In: CONGRESSO NACIONAL DE MILHO E SORGO, 23. Resumos... Uberlândia: SOB (CD-ROM).

BARBIERI JMQ; BRITO CH; DUARTE JM; GOMES LS; SANTANA DG. 2005. Produtividade e rendimento industrial de híbridos de milho doce em função de espaçamentos e populações de plantas. Horticultura Brasileira 23: 826-830.

BRUNINI O 1995. Determinação das exigências térmicas e hídricas de cultivares de milho: In: SEMINÁRIO SOBRE A CULTURA DO MILHO SAFRINHA, 3. Resumos... Campinas: SOB (CD-ROM).
CORDEIRO JC. 2003. Levantamento detalhado do solo do Centro de Ciências Agrárias da Universidade Federal do Piauí. Departamento de Engenharia Agrícola e Solos. Universidade Federal do Piauí.

CRUZ JC; PEREIRA FILHO IA. 2002. Manejo e tratos culturais para o cultivo do milho verde. Sete Lagoas: EMBRAPA, 9 p. (Circular Técnica, 16).

CRUZ JC; PEREIRA FILHO IA. 2003. Manejo e tratos culturais. In: PEREIRA FILHO IA(ed). O cultivo do milho-verde. Brasília: Embrapa Informação Tecnológica. p. 31- 44.

ESTAT. 1993. Sistema de análise estatística (v.2.0). Departamento de Ciências Exatas. Universidade Estadual Paulista. Campus Jaboticabal.

FORNASIERI FILHO D. 2007. Manual $d a$ cultura do milho. Jaboticabal: Funep. 576p.

GUISCEM JM; SANS LMA; GAMA EEG; PEREIRA FILHO IA; CRUZ JC; NAKAGAWA J; ZANOTTO M. 2000. Estimativa da ocorrência dos estádios fisiológicos da cultura do milho pelos métodos de graus-dias e calendário Juliano. In:CONGRESSO NACIONAL DE MILHO E SORGO, 23. Resumos... Uberlândia: SOB (CD-ROM)

MEDEIROS RM. 2006. Climatologia do municipio de Teresina. Teresina: Secretaria do Meio Ambiente e Recursos Naturais do Estado do Piauí. 28p.

LEMOS MA; GAMA EEG; MENEZES D; SANTOS VF; TABOSA JN. 2002. Avaliação de dez linhagens e seus híbridos de milho superdoce em um dialelo completo. Horticultura Brasileira 20: 167-170.

OLIVEIRA MDX. 1997. Comportamento de híbridos de milho no periodo de safrinha no Estado de Mato Grosso. Jaboticabal: UNESP. $88 \mathrm{p}$ (Tese doutorado).

PAIVA JUNIOR MC; PINHO RG; RESENDE SG. 1998. Viabilidade técnica de produção de milho verde na região de Lavras, MG. In: CONGRESSO NACIONAL DE MILHO E SORGO, 22. Anais. Recife: (CD-ROM).

PAIVA JUNIOR MC; PINHO RG; PINHO EVR; RESENDE SG. 2001. Desempenho de cultivares para a produção de milho verde em diferentes épocas e densidades de semeadura em Lavras-MG. Ciência Agrotécnica 25: 1235-1247.

PEREIRA FILHO IA; CRUZ JC; GAMA EEG. 2003. Cultivares para milho-verde. In: PEREIRA FILHO IA (ed). O cultivo do milho-verde. Brasília: Embrapa Informação Tecnológica. p. 17-26.

SANGOI L. 2000. Understanding plant density effects on maize growth and development: an important issue to maximize grain yield. Ciência Rural 31: 159-168.

SILVA PSL; DUARTE SR; OLIVEIRA FHT. 2007. Efeito da densidade de plantio sobre o rendimento de espigas verdes de cultivares de milho desenvolvidas em diferentes épocas. Horticultura Brasileira 25: 154-158.

VIEIRA MA. 2007. Cultivares e população de plantas na produção de milho-verde. Curitiba: UFPR. 78p. (Tese mestrado). 